\title{
MOTIVOS DEL MÁS ALLÁ GRIEGO EN JEAN Y JEAN-PIERRE GIRAUDOUX ${ }^{1}$
}

\author{
Clara Gómez Cortell \\ Universidad de Valencia
}

\section{Resumen}

La saga de los Atridas y especialmente la fase en la que se producela venganza por la muerte de Agamenón y la restauración en el poder de su linaje en la figura de su hijo Orestes, ha sido favorecida por la transmisión de las tragedias griegas y a la par por la tradición clásica. Aquí nos proponemos estudiar en dos Électre, la de Jean Giraudoux y la de Jean-Pierre Giraudoux, un tipo de motivos particularmente relevante en estas obras, en las que la relación con el padre muerto es fundamental, los motivos que remiten al imaginario griego del Más allá.

Palabras clave: Electra, Jean y Jean-Pierre Giraudoux, mundo de ultratumba.

\section{MOTIFS IN THE GREEK AFTERLIFE IN JEAN AND JEAN-PIERRE GIRAUDOUX}

\begin{abstract}
The transmission of Greek tragedies and their classical tradition has cultivated and sustained the Atreides dinasty, and especially the phase in which the revenge for Agamemnon's death and the restauration of the power into his son Orestes occurs. The aim of this study is to analyze the particularly relevant theme of the Greek Afterlife in two Electras, the first one by Jean Giraudoux and the second one by his son JeanPierre Giraudoux, in which the relationship with the dead father and the motifs this one inspires become essential.

Keywords: Electra, Jean and Jean-Pierre Giraudoux, Afterlife.

${ }^{1}$ El presente trabajo forma parte del Proyecto de Investigación FFI2015-63836-P de la Dirección General de Investigación Científica y Técnica del Ministerio de Economía y Competitividad del Gobierno de España. Agradezco a José Vicente Bañuls Oller las sugerencias y consejos en la realización de este artículo; la responsabilidad de la versión que se publica es por completo mía.
\end{abstract}


1. La fase de la saga de los Atridas en la que, tras largos años de espera, Electra, la hija de Agamenón, se reencuentra con Orestes, su hermano, y este lleva a cabo la reparación debida por el asesinato de su padre y con ello se llega a la restauración del linaje del padre en el trono en la figura del hijo ha sido privilegiada por la con frecuencia azarosa transmisión de la literatura griega. En este caso tenemos la suerte de haber conservado obras de los tres grandes trágicos, Coéforas de Esquilo ${ }^{2}$ y las dos Electra, la de Sófocles y la de Eurípides. Este hecho nos permite no solo entender mejor el papel del mito en la tragedia griega, de este y en general de cualquier mito, sino que ha sido y es motivo de múltiples investigaciones que tienden a conocer mejor la dramaturgia de los respectivos autores y los cambios que en ella se van produciendo.

La evolución que en la dramaturgia griega experimenta la figura de Electra, que va desde un personaje muy secundario, simple mediador entre eslabones de un linaje, hasta la protagonista absoluta que urde el plan, anima a su ejecución y ayuda físicamente a que se ultime, así como la exaltación de la relación de Electra con su padre muerto, con la consiguiente fidelidad al fallecido, y por ello a su linaje, era esperable que despertara el interés de públicos de otras época y lugares ${ }^{3}$, también en la literatura francesa, de la que hay excelsos ejemplos, como las dos Électre de los Giraudoux, Jean y Jean-Pierre ${ }^{4}$, obras de las que aquí queremos destacar un aspecto

${ }^{2}$ Es la segunda tragedia en la trilogía Orestíada, precedida por Agamenón y seguida por Euménides, la única trilogía conservada întegra y que mantiene unidad temática, razón por la cual ha sido objeto de estudios especiales.

${ }^{3}$ No debe ser casual que la primera adaptación en prosa en una lengua vernácula de una tragedia griega sea la de Electra de Sófocles por Fernán Pérez de Oliva, Venganza de Agamenón, escrita entre 1512 y 1524, solo precedida en el uso de la lengua vernácula por una adaptación en verso en italiano de Hécuba de Giovanbattista Gelli en torno al 1519. Probablemente influido por la obra de Pérez de Oliva escribiera García de la Huerta su Agamenón Vengado (publicada en 1768), en este caso en verso, una de las obras más relevantes del neoclasicismo español. Muchos autores han creado sus respectivas Electras, como Hugo von Hofmannsthal, O'Neill, Hauptmann, Tawfiq Al-Hakim... En España, José María Pemán, Alfonso Sastre, Josep Palau i Fabre, Arcadio López Casanova, Domingo Miras, Lourdes Ortiz, Fermín Cabal, Raúl Hernández, Itzíar Pascual, Lluïsa Cunillé, Carlos y Ricardo Iniesta, entre otros; en Iberoámerica Virgilio Piñera, Sergio De Cecco, Nelson Rodrigues, Gabriela Mistral, Enriqueta Ochoa, Albalucía Angel, Magaly Alabáu, Aida Cartagena Portalatín... En lengua francesa, entre otras, cabe destacar las de Longepierre, P.-J. Crébillon, Guillard, Chénier, Voltaire, Soumet, Yourcenar, Sartre, Anouilh, etc., así como las traducciones libres de Leconte de Lisle y de A. Dumas; para las adaptaciones francesas remitimos a Bonnéric (1986). A todos ellos se han dedicado estudios que arrojan luz sobre el modo en que en cada momento el mito griego es utilizado con finalidades distintas, acordes con la voluntad del autor, como también sucedía en la literatura griega.

${ }^{4}$ En este trabajo seguimos los textos de Jean Giraudoux (1985) y Jean-Pierre Giraudoux (1965) - primera edición de su Électre-. A partir de ahora nos referiremos al padre mediante J.G. y al hijo mediante J.-P. G. 
concreto, pero esencial para la comprensión de esas recreaciones ${ }^{5}$. Debemos, sin embargo, hacer un rápido repaso a los elementos esenciales de la saga y de esta fase concreta que nos ayuden a entender el interés de los autores posteriores, particularmente los Giraudoux, y las complejas relaciones que establecen en sus respectivas obras con los modelos griegos. Aunque hagamos referencia general a la saga, nos centraremos para hacerlo en especial en aquellos motivos que muestran el imaginario griego del Más allá, elementos de la geografia infernal que aparecen no solo en obras literarias ${ }^{6}$ y que mantienen su vigencia en obras muy posteriores ${ }^{7}$; iremos a la par, cuando sea posible, mostrando la permanencia o cambio de esos motivos infernales en las obras que aquí nos ocupan.

2. El personaje de Electra, como deciamos, experimenta un proceso que lleva en la época clásica a darle mayor relevancia hasta el punto de que sea el personaje principal en Euripides, frente a lo que sucedia en los primeros textos literarios griegos ${ }^{8}$. Es probable que fuese Estesícoro el primero en dar una cierta relevancia a Electra en su poema Orestíad $a^{9}$, donde utiliza el nombre Electra en lugar de Laódice, el nombre que ofrece otra tradición, y lo explica mostrando una etimología que nos informa de un componente

\footnotetext{
${ }^{5}$ La bibliografia sobre la producción de J.G. es ingente, particularmente sobre su Électre; no lo es tanto la de su hijo, J.-P. G. Aquí nos proponemos centrarnos en un aspecto que, en nuestra opinión, no ha sido objeto del merecido estudio sistemático, sino que solo aparecen de manera dispersa algunos comentarios a motivos o referencias de las que no se ha extraído toda la información que pueden aportar.

${ }^{6}$ En obras de diverso tipo se describe el Más allá, el reino de Hades, de las que cabe destacar por la gran información que aportan obras como la tragedia Alcestis de Eurípides, cuya protagonista muere en escena (en lugar de su esposo) describiéndonos el proceso; la comedia Ranas de Aristófanes, donde un atribulado Dioniso, que lamenta la muerte de Eurípides, acude al Hades para sacarlo de allí; diálogos platónicos como Fedón o República y otros textos más tardíos de Plutarco, Pausanias, Luciano. Con todo hay un tipo de textos especiales, las lamellae aureae, laminillas de oro inscritas en la corriente religiosa órfica, que se depositaban en las manos o la boca del difunto y que debian guiarle en su viaje al Más allá. Cf. Bañuls Oller (1997: 5-22). Para el complejo imaginario griego sobre el Más allá, cf. Brioso Sánchez (1995: 1-53), con abundante bibliografia, donde se muestra la complejidad de los diferentes estratos que ofrecen los textos y la evolución que comportaron los cambios sociales y culturales que se produjeron en Grecia, y Jouanna (2015), que estudia los diferentes motivos a lo largo de toda la época clásica.

${ }^{7}$ Un caso paradigmático de esta permanencia es la que se observa en la trilogía El reino de Celama de Luis Mateo Díez, estudiada por Bañuls Oller (2017b) y Bazán Rodríguez (2015: 72-93).

${ }^{8}$ Para su creciente papel en la literatura griega, relacionado con el proceso de reparación de la muerte de Agamenón, cf. Bañuls Oller (2017a: 65-82).

${ }^{9}$ Estesícoro es un citaredo, perteneciente a la misma tradición de la que bebe la épica homérica, del que quedan muy pocos fragmentos, de los cuales se desprende que ejerció una fortísima influencia sobre Esquilo, como en el caso de la saga de Edipo; cf. Morenilla Talens y Bañuls Oller (1991: 63-80) y Suárez de la Torre (1993: 53-62).
} 
importante de su papel, "la que permanece sin lecho, sin ser desposada", es decir, una mujer que vive en una situación anormal. Esta anormalidad se mantiene en la versión de Esquilo y Sófocles, pero también en la de Eurípides, aunque de un modo diferente, puesto que ha sido casada solo formalmente con alguien que no es de su condición, aspecto que han recreado los dos Giraudoux, aunque con la variante de que la tragedia de Eurípides empieza con una Electra casada hace ya algún tiempo mientras que los Giraudoux la comienzan el dia de la boda, pero en ambos casos con alguien que no es de su nivel social, el jardinero de palacio en la obra de J.G., en el caso de la de J.-P. G. un campesino, que también ha prometido no tener relaciones intimas con ella, y con la misma finalidad que en la obra euripídea: en J.G. a preguntas de Egisto ella acepta, aunque la madre se opone, y por una compleja peripecia, en la que se halla implicado Orestes, no llega a realizarse, mientras que en J.-P. G. es ella la que elige el esposo como parte de un perverso plan y el matrimonio se consuma.

De lo poco que los fragmentos permiten saber, entre otras innovaciones, Estesícoro introduce en la saga a las Erinias y da una forma infernal al sueño premonitorio de la madre: Clitemnestra sueña con la llegada de una serpiente, un animal que pone en contacto el mundo de los vivos y el de los muertos, es decir, sueña con el regreso del esposo muerto o de alguien que le representa. Estos dos motivos vinculan la saga con el mundo de ultratumba. El primero, la presencia de las Erinias, de unos seres infernales que viven en el Hades, encargadas de velar por el cumplimiento de la reparación debida cuando se produce un delito de sangre en el mismo linaje y que en la obra final de la trilogía Orestíada de Esquilo son incorporadas y asimiladas a la vida política ciudadana, transformadas en Euménides, en protectoras de la $\operatorname{ciudad}^{10}$. Por ello también aparecen al final de la Electra de Eurípides, momento en el que dan comienzo a la persecución de Orestes y vemos cómo la continúan en el comienzo del Orestes del mismo autor. De ellas se sirve J.G. desde el comienzo de su obra y en diferentes momentos de un modo muy peculiar, como comentaremos.

El segundo elemento es la presencia del sueño premonitorio en forma de serpiente, un animal reconocido por los griegos como ctónico, que vive bajo tierra, en contacto con los muertos; un sueño que vuelve a aparecer en Esquilo, en la forma de una serpiente que mama leche y con ella un coágulo de sangre del pecho de Clitemnestra, y del que quedan rastros en J.G. cuando el Jardinero, que intenta deshacerse de 'Les Petites Euménides',

${ }^{10}$ Es en Esquilo donde aparece la primera caracterización clara, incluso física, de estas deidades infernales y de ella beberán los sucesivos autores; para esa presentación en Esquilo cf. De Santis (2013: 11-48). 
les espeta "Cette fois, taisez-vous, sales petite vipères!" y poco después "Affreuses petites bêtes. On dirait trois petites Parques!» (págs. 19-20). También mantiene J.G. el motivo del sueño, aunque profundamente modificado, al que también nos referiremos más tarde.

Tras esas apariciones menores de Electra en la literatura arcaica, Esquilo le da un papel de cierta relevancia en su Coéforas, donde la convierte en la hermana que espera fiel al padre y al hermano, un papel pasivo frente al que adquiere Orestes, quien desde el comienzo de la tragedia se muestra deseoso de mantener la relación con su padre muerto: con una invocación a él empieza la obra, reclamando la unión con la estirpe. Electra asume el papel de salvaguarda de la relación entre el padre muerto y el hermano. El escenario contribuye a mostrar la unión: la escena está dominada por la tumba del padre, a la que llega un camino desde el palacio, por el que entran Electra y el coro, y otro por el que los hombres vienen de fuera. También desde el comienzo de la Électre de J.G. sentimos la presencia de esa tumba: el Jardinero informa al Extranjero, realmente Orestes, de que la habitación de Electra es la más alta porque desde su ventana ella puede ver la tumba de su padre (pág. 13).

En la tragedia de Esquilo en cuanto Orestes se da a conocer como lo que es, como el heredero, y expone el plan de venganza, Electra queda sin papel en la obra: ella es la víctima inocente que solo espera sin siquiera rebeldía. Por esa razón tampoco hay lugar para un debate madre-hija, como sí habrá en las recreaciones de Sófocles y Eurípides, de las cuales beberán los Giraudoux. En Sófocles y Eurípides Electra adquiere un papel mucho más relevante, aunque considerablemente distinto, en la misma medida en que también es distinto el papely carácter de los dos Orestes y la finalidad de las obras. En Sófocles sigue siendo una víctima que sufre por acción de unos o de otros: su esencia es el recuerdo del padre asesinado y la constante espera del regreso del hermano. Pero no adopta el papel pasivo de Esquilo, sino que actúa como actúan las mujeres griegas, a través de la palabra: sus constantes desaires e insultos a los reyes son la causa de que vaya a ser encerrada en una habitación de la que no podrá volver a salir ${ }^{11}$. La llegada del hermano hace que su papel activo quede relegado a un segundo plano, lo que no sucede en Euripides.

Desde el comienzo Eurípides priva a la obra de todo rastro de heroísmo, le da un aire de cotidianeidad que especialmente J.G. incorpora a la suya: Electra es una campesina a la que se ha casado con un hombre ajeno al

${ }^{11}$ Cf. Bañuls Ollery Crespo Alcalá (2003: 31-102), Bañuls Oller, Crespo Alcalá y Morenilla Talens (2007) y Morenilla Talens (2016: 16-34). 
mundo heroico para evitar que pudiera tener descendencia noble ${ }^{12}$. Como indicamos, con modificaciones, el motivo de la boda reaparece en los dos Giraudoux, en el caso de J.G. con la misma finalidad que en Euripides, no así en J.-P. G., donde es ella la que decide. La Electra euripídea muestra un odio feroz contra Clitemnestra hasta el punto de que es ella la que obliga, incluso físicamente, a Orestes a matarla, aspecto este del odio a la madre que con matices se puede observar en las obras francesas: en J.G. muy claramente, puesto que la odia sin que sepa aún del asesinato del padre; en el caso de J.-P. G. hay un odio mezclado con repulsión, sin que tampoco medie el asesinato del padre, del que no son responsables los reyes, aunque paguen por ello.

3. De un personaje indefenso, que no puede ni siquiera discutir, que se limita a lamentar la situación en que vive, en Coéforas de Esquilo, Sófocles crea un personaje cuya esencia es el recuerdo y la espera, y al llegar el hermano le cede el protagonismo; Euripides convierte esta sufriente muchacha en una mujer llena de odio, cuya fuerza y dominio de la situación es tal que incluso es ella quien empuja la mano de Orestes en el cuerpo de la madre. La literatura posterior ha combinado con frecuencia rasgos de estas dos últimas, la de Sófocles y la de Eurípides, interesada por la resistencia al olvido y por la tensión dramática que provoca en Orestes el conflicto moral y afectivo del matricidio, un conflicto tan difícil de mantener que con frecuencia los autores intentaron evitar el matricidio, o al menos el matricidio consciente, como veremos que hace J.-P. G. ${ }^{13}$ Precisamente esta es la situación de la primera obra francesa que puede considerarse una adaptación de la saga, no una traducción libre, la Électre de P.-J. Crébillon (1708), en la que Orestes tiene por padre a Egisto, como sucede en J.-P. G., y dirige su venganza solo hacia él, pero, inadvertidamente, mata a su madre, motivo que

\footnotetext{
${ }^{12}$ Es este campesino quien inicia la obra explicando al público lo que ha sucedido y nos informa de que él ha respetado la posición de Electra y no ha consumado el matrimonio. Inmediatamente después sale Electra, dedicada a las labores cotidianas de una ama de casa, lamentándose de la dureza de las condiciones de vida de un campesino normal del Ática, en este momento unas condiciones duras por el estado en que se encontraba Atenas después de los años de guerra y las constantes derrotas y destrucciones que provocaron el empobrecimiento de la mayoría de la población.

${ }^{13}$ Sin duda tuvo mucho que ver en épocas anteriores el pensamiento cristiano, que en modo alguno puede justificar un crimen de este tipo; y por esa misma razón, se intentaba descargar a Clitemnestra de la responsabilidad. No creemos que sea esa la causa en J.-P. G., sino más bien la especial orientación que este autor da a su obra, el profundo pesimismo sobre la marcha de la sociedad que rezuma y que son la causa de que una ciudad aparentemente tranquila y bien gobernada sea capaz de asesinar al campesino esposo de Electra y que al final de la obra, tras el complejo entramado de ardides cortesanos, mueran unos reyes que no son responsables del asesinato.
} 
con modificaciones es seguido por Voltaire (Oreste, 1750), donde la madre es alcanzada cuando quiere evitar el golpe contra Egisto ${ }^{14}$.

La relación de las obras de los Giraudoux con los referentes griegos, particularmente la de J.G., han sido estudiadas con acierto, como puede verse en numerosos trabajos ${ }^{15}$, en algunos de los cuales se ha puesto de manifiesto el claro contenido político de la obra, lo que en absoluto era ajeno al teatro griego ${ }^{16}$. Creemos, sin embargo, que no se ha dado la importancia que merece a la clara presencia del imaginario griego del Más allá en estas dos obras, fruto de autores de una amplia cultura bien asentada en los fundamentos de la tradición clásica grecolatina, que sin duda eran conocedores de los textos más relevantes y difundidos entre los estudiantes de letras en los que se muestra la geografia infernal griega, por no hablar del conocimiento indirecto, a través de las katábasis de Virgilio y de Dante ${ }^{17}$. Ya hemos hecho referencia a algunos motivos al hilo de la presentación de la saga; ahora quisiéramos dar algunos más que son acordes a los que hasta ahora hemos indicado.

Por lo que hace a la Électre de J.G., ya hemos comentado la importancia que en la escena inicial se da a la relativa cercanía del palacio a la tumba de Agamenón. Con esa referencia al deseo de Electra de ver, de tener siempre presente la tumba del padre, a pesar de que, como se va mostrando en el desarrollo de la obra, se desconoce que Agamenón haya sido asesinado, y con el hecho de que en las primeras palabras de la obra se hable en extenso de la peculiar fachada del palacio, hay un deseo por parte del autor de crear una relación muy estrecha entre Electra y su padre y de evocar a la vez a Esquilo y a Sófocles: por una parte, trae ante nosotros, aunque no la veamos, la tumba que en Esquilo formaba parte del escenario, y, por otra, la fachada del palacio, que tanta importancia tiene en Sófocles, un palacio que aquí adopta un peculiar aspecto. La clara diferencia entre el palacio que existía antes de la muerte de Agamenón y el que se construyó después, los materiales utilizados y el hecho de que parezca que una parte rie mientras la otra

${ }^{14}$ Sobre el motivo de la venganza de Orestes y las formas que adopta en diferentes literaturas, cf. Frenzel 19928: 598 ss., s.v. 'Orestes Rache'. Para la repercusión de la innovación de Crébillon en un autor fuertemente influido por la literatura francesa, P.P. Martello, cf. Morenilla Talens (2013: 126 n. 40) y Morenilla y Bañuls (2014: 219-1232).

15 Solo a modo de ejemplo, y teniendo en cuenta que, como hemos señalado, la bibliografia es muy extensa, cf. Bravo Castillo (2008: 67-81), Luengo López (2013: 201-231), Brunet (1978), Michel (1998), Albérès (1962). No debe, con todo, olvidarse el peso del propio teatro francés, como hemos señalado con respecto a la muerte de la madre y que puede verse en otros detalles de ambas tragedias, en los que no nos es posible detenernos.

${ }^{16}$ Es el caso del estudio de Jufresa Muñoz (2006: 269-284).

${ }^{17}$ Para un rápido repaso a la presencia de este motivo en diversas literaturas, cf. Frenzel (19924: 713 ss.), s.v. 'Unterweltsbesuch'. 
llora (pág. 10) no pueden más que hacer pensar en la imagen de reflejo en el espejo que adopta el mundo infernal griego. Posteriormente, en el diálogo entre el Jardinero y el Presidente que intenta convencer al Jardinero de que no debe casarse con Electra, se habla de la visita que a diario hace la joven a la tumba de su padre (pág. 24), visita que se realiza por las noches, con lo que se está evocando una más intensa relación con el mundo de las sombras.

Se ha señalado, con razón, la originalidad de las Erinias de J.G., 'Les Petites Euménides', muchachas que van creciendo a la par que se va acercando el momento del cumplimiento de la venganza ${ }^{18}$. Su presencia en escena, cuando ni siquiera se conoce que Agamenón haya sido asesinado, es un presagio y vienen a cumplir en cierto modo, junto con el Mendigo, el papel del coro griego. En las tragedias griegas, tanto en Esquilo como en Eurípides, son un coro, es decir, un grupo compacto de doce coreutas, pero la tradición desde la misma antigüedad clásica transmite que podian ser tres, como aparecen incluso en la iconografia, lo que es acorde con el número que utiliza J.G. Son la representación del odio que, sin razón conocida, siente Electra por su madre, un odio que la lleva a un comportamiento irresponsable en el sentido de que sus actos, no motivados por un conocimiento real de la situación, provocan la desgracia; una aversión a la madre y amor irracional al padre desde el comienzo de su vida que es una especie de premonición de lo que más adelante conocerá, con una clara influencia de las teorías freudianas ${ }^{19}$.

Esa especie de premonición se verá confirmada en el sueño de Electra, un sueño que a la vez evoca los sueños que tiene Clitemnestra en Esquiloy Sófocles, pero se aparta de ellos: no es Clitemnestra la que sueña el regreso de Orestes, sino Electra la que ve en sueños el espectro de su padre que le habla del asesinato, hasta ahora desconocido (pág. 112), y lo hace cuando ella ya ha recuperado al hermano. Esta visión en sueños del espectro del

${ }^{18}$ En la literatura posterior es frecuente el uso indiferente de los nombres Erinias y Euménides, o bien Furias, personajes que tienen una presencia muy destacada en la literatura y el arte dramático francés, como podemos ver, por ejemplo en los versos finales de la Andromaque de Racine, descritas en los vv. 1635-1644, acosando a Orestes, pero no por la muerte de su madre, sino por haber matado a Pirro, el hijo de Aquiles, a petición de una enajenada Hermíone. Racine, por lo tanto, las saca a escena en una saga diferente, aunque el personaje que las sufre sea el mismo, pero podemos verlas en sagas diferentes, como es el caso de la tragedia lírica Idoménée de A. Danchet (música de A. Campra). Con ellas se representa en estas obras de modo plástico los remordimientos del asesino, incluso antes de que el crimen tenga lugar, donde representan las dudas ante la gravedad del asesinato. Para una panorámica de ese cambio en el ámbito de la saga de los Atridas y su presentación en una obra relativamente reciente, cf. Morant Giner (2016: 123-146).

${ }^{19}$ En las recreaciones de esta saga de los siglos xviii y xix va aumentando el odio que Electra siente por su madre, un odio primitivo, a la par que se van desarrollando los aspectos psicológicos de esta relación, motivo que será muy productivo ya en el siglo xx, como puede verse en la Elektra de Hofmannsthal-Strauss (1904). 
padre asesinado no puede más que hacernos pensar en Hamlet, tragedia cuya relación con la saga de los Atridas ha sido bien estudiada y en la que el espectro del padre aparece informando de la verdad y reclamando venganza, aunque no se trate, como aquí, de un sueño ${ }^{20}$. En la literatura griega no son extrañas las apariciones espectrales, las sombras de los muertos que aparecen para informar a los vivos o para pedir la reparación de su muerte, como podemos ver en Persas de Esquilo, donde la sombra de Darío, invocada por su esposa Atosa, informa del trasfondo, de la causa real de la derrota de Jerjes; o en Euménides, en cuyo inicio es el espectro de Clitemnestra el que despierta a las agotadas Erinias para que sigan persiguiendo a Orestes; uniendo en cierto modo ambas funciones la sombra del joven Polidoro aparece en el prólogo de Hécuba de Eurípides informando a los espectadores de su muerte y de las futuras desgracias que va a sufrir su desdichada madre ${ }^{21}$. Prueba de la creencia en la posibilidad de que los muertos se aparecieran a sus seres queridos en sueños es la presencia de este motivo en epitafios de niños, como los dedicados a Paula y Menandro (gv 1545 y gv 1923 ii) ${ }^{22}$.

Ese sueño espectral de Electra también en cierto modo es el cumplimiento de los ruegos de la joven en la Electra de Sófocles a su hermana Crisótemis: le pedía que no hiciera en la tumba del padre las libaciones que le ha ordenado la madre y en su lugar depositara sendos bucles de sus cabellos y suplicara al padre que acudiera a socorrerlas para lograr la victoria en la lucha que se ha de iniciar (vv. 453-456). Ese espectro, que no aparece en la Electra sofoclea, surge en cambio en la de J.-P. G. en la forma de sueño.

Pero además de lo que hemos comentado y más allá de las afirmaciones explícitas de que se desea la muerte de una u otra persona, o la comparación tan elocuente que el Mendigo hace de la boda de Electra y el Jardinero con el deseo de su muerte por parte de Egisto (págs. 38-39), llama la atención que desde el comienzo mismo de la obra Electra sea caracterizada por su relación con el mundo de ultratumba. Ya hemos señalado sus visitas nocturnas a la tumba paterna; poco después el Jardinero indica que «Électre est pieuse. Tous les morts sont pour elle" (pág. 27), pero lo que ahora nos

${ }^{20}$ Para la estrecha relación entre Hamlet y Orestes, cf. Carvalho (2015: 363-372). Para el motivo de la visita en sueños de un espectro cf. Frenzel (19924: 802-830), s.v. 'Weissagung', 'Vision', 'vorausdeutender Traum'.

${ }^{21}$ Para un estudio de las apariciones de fantasmas en la tragedia griega y en la iconografia, cf. Aguirre Castro (2006: 107-120). Es importante tener en cuenta la gran influencia que durante siglos tuvo la tragedia Hécuba, de las que muy pronto se hicieron varias traducciones y adaptaciones al francés y a otras lenguas, por las razones que son estudiadas por Garnier (1999) y Morenilla Talens (2014).

22 En gv 1545 una atribulada madre acaba pidiendo a los dioses de ultratumba que dejen que su hija despierte, aunque sea en sueños; y en gv 1923 ii el propio difunto dice que se aparece en sueños a su madre para consolarla. Cf. Peek (1955: 461 y 591 respectivamente). 
interesa es la caracterización que de Electra hacen los otros personajes, una caracterización, a rasgos dispersos, que evoca a los muertos:

- El Presidente se refiere a su inacción: «Elle ne fait rien. Elle ne dit rien. Mais elle est là» (pág. 22).

- Cuando entran en escena por primera vez, juntas, Clitemnestra y Electra (pág. 47), las presenta el Presidente con "Les voici toutes deux", a lo que responde la madre "Toutes deux est beaucoup dire. Électre n'est jamais plus absente que du lieu où elle est" y poco después, cuando Egisto va a exponer la decisión de casarla, se refiere a ella insistiendo en ese aspecto, en su ausencia, de un modo nuevo, añadiéndole un motivo que la asimila aún más al mundo de ultratumba, el miedo a que los muertos despierten:

Depuis longtemps tu nous inquiètes. Je ne sais si tu t'en rends compte: tu n'est plus qu'une somnambule en plein jour. Dans le palais et dans la ville, on ne prononce plus ton nom qu'en baissant la voix, tant on craindrait, à le crier, de t'éveiller et de te faire choir...

- Poco después el mismo Egisto le echa en cara: "Nous faisons une situation fausse aux morts en les raccrochant à notre vie", y en la misma escena, en la discusión entre el Jardinero y Clitemnestra, en la que la madre no quiere esa boda e intenta disuadir al novio, incluso con amenazas, se insiste en que nunca sonrie: «Je n'ai jamais vu sourire Électre».

- Electra es lo contrario a la alegría de vivir, una joven que siempre está en contacto con los muertos, que no sonríe nunca, que, como señala Hamburger "Sie ist im Staate Ägisths und Klytemnestras das störende Element, weil sie das hassende und damit das lebensfeindliche Prinzip repräsentiert" (1962: 74). Por ello, aunque el Jardinero espera que en contacto con sus flores y sus plantas, con aquello que crece y florece, Electra pueda ser feliz, esto no será posible.

Electra está tan alejada de las alegrias de la vida y tan cerca de su padre, cuya tumba, como un alma en pena, visita todas las noches, que es descrita por los demás como un muerto: inactiva, siempre triste, ausente como un sonámbulo, una persona a la que se teme despertar, como se teme despertar a los muertos. Todos ellos son rasgos que caracterizan las sombras de los fallecidos con las que podrá conversar Ulises en el Canto ix de Odisea tras cumplir con un ritual necromántico, atraerlas a una de las puertas del Hades y darles un soplo de vida durante un instante permitiendo que beban la sangre del sacrificio que acaba de realizar ${ }^{23}$. La caracterización del alma del

${ }^{23}$ Aunque habitualmente se habla de la katábasis de Ulises, en realidad él no entra en el Hades, como sí harán Virgilio y Dante, sino que hace salir a las almas mediante ese ritual 
muerto como una sombra sin vigor, sin memoria, que puede vagar apenada y cuyo contacto se evita salvo en circunstancias muy especiales ${ }^{24}$, es propia de la época griega arcaica, pero se mantiene en numerosas referencias literarias e iconográficas posteriores, incluso cuando las religiones mistéricas han introducido ya otras ideas, como la de la metempsícosis ${ }^{25}$.

4. Esa misma intensa relación con los muertos es mantenida e incluso acrecentada por J.-P. G. en su Électre, dedicada a su padre y publicada en 1965. Se trata de una obra con notables divergencias con respecto a la del padre, no solo en el tono, pero también con similitudes, algunas de las cuales ya hemos señalado. Desaparece el coro de Euménides, la gran innovación paterna, que es sustituido por un coro más convencional: tres hombres y tres mujeres del séquito de Egisto y de Clitemnestra, que hablan individualmente entre sí y que no pueden aportar información especial, solo comentan la que van conociendo ${ }^{26}$. También desaparece el Mendigo, que junto con las Euménides, hacía en parte la función del coro griego. Aquí, en cambio, aparece un personaje ajeno a la saga, que complica la trama al modo de Racine o Crébillon, Anaxobia, hermana de Agamenón y madre de Pílades, intrigante y perversa, el verdadero motor de toda la acción y, según las deducciones del coroy la afirmación de Electra al final de la obra, la asesina de Agamenón, de su propio hermano.

Por lo que hace al aspecto concreto que aquí nos interesa, la presencia de motivos del Más allá es aún más intensa que en el caso de la Électre de J.G. y no solo en lo que hace a la descripción de Electra, sino también en cómo percibe ella la realidad.

Electra es presentada siguiendo la línea de la figura que creó J.G., pero con una relación con el mundo de ultratumba aún más acentuada: es una especie de reflejo en negro de su madre. No aparece hasta la escena vi del

que les proporciona durante unos instantes la vitalidad suficiente para poder recordar lo que fueron. En Odisea x 504-540 describe Circe el viaje hasta las puertas del Hades y el ritual que ha de seguir para poder hablar con las almas y el Canto xi se dedica íntegro al viaje hasta esa puerta y su encuentro con las almas, lo que es prueba de la importancia que Homero confiere a esta aventura, en realidad la aventura más peligrosa a la que un héroe se puede enfrentar, como han señalado algunos estudiosos para los que este episodio formaría parte de los textos más antiguos de la Odisea (por ejemplo Carpenter, 1946).

${ }^{24}$ Por ejemplo, durante las Antesterias, fiestas atenienses en las que se dejaba comida para que los familiares muertos acudieran a comer de ella. Es un modo de mantener bajo el control de una fecha determinada el deseo de los muertos de volver a la vida.

${ }^{25}$ Entre otras es el caso de los órficos, de los que se observa una notable influencia en Platón; cf. Bañuls Oller (1997: 5-22) y Bernabé Pajares y Casadesús i Bordoy (2008).

${ }^{26}$ En la escena xi del Acto iii cuando van a enfrentarse Orestes y Egisto, uno de los hombres le da una jabalina a Egisto y otro a Orestes otra, momento en el que, con ironía, una de las mujeres dice "Nous servons enfin à quelque chose!" (pág. 195). 
Acto i; hasta ese momento solo tenemos las referencias que hacen sobre ella los restantes personajes, como es el caso del bello y superficial Pílades, que triunfa en todos los salones de Argos, pero "Je n'ai pas fait sourire Électre" (pág. 15); pero tampoco llora, como más adelante dirá una mujer del coro: "Électre ne pleure jamais" (pág. 61). Impasible, como si de un muerto se tratara.

Su aparición es presentada con la siguiente indicación del autor: "Électre est tout de noir vêtue. Sa robe est-elle l'élégance ou la simplicité qui, de façon étrange, ressemble un peu - parce qu'elle est son contraire-à la robe rouge de Clytemnestre?" (pág. 50). Frente a una Clitemnestra que ama la vida, los colores, las ropas bonitas... y que por ello ha de olvidar, olvidar a aquellos a los que Agamenón le mató, Tántalo e Ifigenia, olvidar la muerte de Agamenón y la de Orestes, frente a esta Clitemnestra se alza Electra, que solo ama a los muertos, comoleemos en boca de su madre: "Tun'es capable que d'aimer des ombres. Tu aimes ton père, tu aimes Oreste. Tu épouses un berger comme si tu te tuais. Depuis quinze ans, tu as choisi la mort" (pág. 53). Para ella empiezan a tener sentido el padre y el hermano cuando mueren: "Tu n'as rien compris, mère, Mon père vivant m'aurait peut-être été indifférent et le petit Orestes pouvait m'exaspérer. Leur mort a tout changé. Pour moi, ils sont nés de leur mort" (pág. 58) ${ }^{27}$. No es de extrañar que una mujer del coro exclame "Moi, je la trouve sinistre" y le responda un hombre "Elle est trop noire. Vive la blondeur de Clytemnestre!" (pág. 59).

Uno de los hombres del coro habla de ella en términos que la vinculan con la muerte en dos parlamentos de esta misma escena en la que madre e hija se han definido por contraste. Así, por contraste, la sigue caracterizando el Premier Homme cuando la recuerda en los funerales de Agamenón, junto a su hermano "ceinte de blanc, le visage de marbre, Électre ne voyait que le mort", o bien junto a su madre, vestida de rojo en una ceremonia, "une adolescente passait, muette, raide, absente, et les vérités du jour, soudain, devenaient incertaines" (pág. 63).

Una Electra que se casa con un campesino que le ha asegurado que no la tocará, porque "Car moij'ai su, je saurai résister àla vie» (pág. 54)²8. Yen

\footnotetext{
${ }^{27}$ Como en el caso de J.G. no se sabe que Agamenón haya sido asesinado, pero su muerte es utilizada para culpar a unos u otros: Anaxobia culpa a Egisto para lograr que Clitemnestra lo odie y tome como amante a su hijo Pílades; ante Orestes, decidido a matar al asesino, se autoinculpan Clitemnestra y Egisto para evitar la muerte del otro, lo que no consiguen, aunque, como dijimos, Orestes no pretende matar a su madre, pero esta se abalanza sobre Egisto en el momento en que Orestes lanza la jabalina sobre él de modo que mueren ambos.

${ }^{28}$ Esta Electra pretende hacer lo contrario que su madre ha hecho: frente a su unión con Egisto y con los numerosos amantes que Anaxobia le proporciona, ella pretende mantenerse virgen, aunque después será ella la que buscará el contacto íntimo con el campesino.
} 
conversación con Egisto, ya al final del Acto i (pág. 72), señala una nueva causa para esas bodas: Egisto hizo enterrar a su padre fuera de la ciudad, en un lugar que a ella le costó encontrar, del que dice "La maison de mon futur époux est près de la tombe de mon père». La tumba del padre, de nuevo: ahora no es visible desde el palacio, como en J.G., sino que la tendrá cerca en su futura casa.

De sí misma habla en la escena ix, Acto i, en discusión con Egisto, un Egisto que simboliza al buen gobernante, que durante los quince años que median de la muerte de Agamenón, se ha esforzado por transformar Argos, lo que al final verá que no ha conseguido. En sus palabras, Electra muestra su relación con el mundo de ultratumba, con el pasado:

Car la folle Électre ne songe qu'au passé quand Egisthe construit l'avenir du peuple. Car la cruelle Électre ne rêve que de guerre quand Egisthe travaille pour la paix. Électre, par son deuil obstiné, revêtait un masque provocant (pág. 71).

Pero más allá de estas referencias a la cercanía a los muertos de Electra, especialmente interesante nos parece el modo en que ella ve su ciudad en un parlamento en el que, a la par que vuelve a confrontarse con su madre, describe Argos como el mundo de ultratumba, sin colores, solo formas, solo sombras, en el que ella es a la vez aquello que no muere y que muere y renace, esto es, ella es lo que permanece inalterable:

Ma mère se dit sensible à la beauté quand un regard la charme, quand un vêtement la trouble, quand des couleurs lui parlent ${ }^{29}$. Ce que je vois, moi, ce que j'accepte de voir, est loin de la beauté et hors de la laideur. Je perçois des formes, je sens des mouvements. Je m'abandonne aux vents. Argos s'offre à moi avec ses pierres, ses champs, son ciel, et sans aucune chair. Je suis la sœur des minéraux, des végétaux, de tout ce qui ne meurt pas, de tout ce qui renait. Et si ma robe est noire, ce n'est pas que je porte deuil comme tous ici le croient et vous d'abord. C'est pour être, comme une ombre, la seule vraie fille d'Argos. C'est que, sous le soleil comme au cœur de la nuit, Argos est pour moi sans couleur, sans musique, sans cette affreuse vulgarité des couleurs et des rires dont vous saoulez le peuple. L'âme d'Argos n'est pas dans son peuple, Egisthe, mais dans des lignes presque abstraites, qu'aucune politique ne saisira jamais et quela pensée fuit (pág. 71).

Esta descripción de un mundo sin colores será retomada después por uno de los coreutas en una intervención dirigida a los miembros del coro

${ }^{29} \mathrm{La}$ insistencia en el contraste entre el gusto por los colores de la madre frente a su predilección por el negro, además de esta función de acercarla al mundo de ultratumba, crea un juego de referencias con la importancia de las visiones en color o en blanco y negro por parte de otra protagonista de J.G., Helena en La guerre de Troie n'aura pas lieu. 
en medio de la discusión entre Electra y Orestes, cuando Electra intenta convencer a Orestes de que debe matar a Egisto. Ante la afirmación de Electra "Tu es mon frère parce que - j'en suis sûre déjà- tu jettes sur le monde le même regard que moi", el hombre del coro se pregunta: "Oreste voit-il, comme Électre, un monde sans couleurs?" (pág. 125).

Tras la muerte de Egisto y Clitemnestra a manos de un indeciso Orestes, que busca la mirada imperativa de Pílades, y tras el suicidio de Anaxobia, que ve frustrados todos sus planes y los sufrimientos de tantos años, Electra pide al coro que permanezca junto a ella mientras pronuncia su parlamento final, dirigido a la que fue el motor de toda la trama, a Anaxobia, y una vez que ha anunciado sus bodas con Pílades, exclama "Ah! Que la nuit est claire!", a lo que replica un coreuta "Qu'allons-nous devenir, Électre, si tu

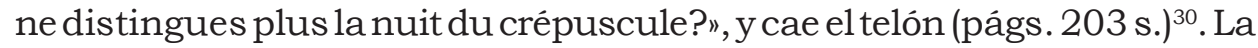
obra acaba en el crepúsculo, volviendo el autor a evocar el Más allá, puesto que en la geografia mítica el mundo de ultratumba está ubicado donde el sol se esconde, en el lugar del crepúsculo, aquello que Electra ve.

5. Electra, la hija que guarda fiel la memoria del padre, fue del agrado de numerosos autores a lo largo de los siglos; la joven resistente al olvido, la no acomodaticia, que despliega ante su madre y su acompañante un odio no siempre motivado, es una figura que se ha prestado a interpretaciones muy variadas, incluyendo las psicológicas. En la configuración de los nuevos personajes en las dos Électre de Jean y Jean-Pierre Giraudoux hemos podido analizar algunos motivos, relacionados con la visión que del Más allá muestra la literatura griega, que adquieren gran relevancia y cuya percepción confiere a las obras una profundidad mayor.

\section{Bibliografia}

Aguirre Castro, M. (2006): «Fantasmas trágicos: algunas observaciones sobre su papel, aparición en escena e iconografia». Cuadernos de Filología Clásica. Estudios Griegos e Indoeuropeos, 16, págs. 107-120.

Bañuls Oller, J.V. (1997): "De la pétrea memoria y el áureo olvido. Los epitafios y las lamellae aureae». Studia Philologica Valentina, 2, págs. 5-22.

- (2017a): "La sombra del poder: Egisto». Cuadernos de Filología Clásica. Estudios Griegos e Indoeuropeos, 27, págs. 65-82.

- (2017b): "La geografia infernal griega en El reino de Celama de Luis Mateo Diez». Euphrosyne (en prensa).

${ }^{30}$ La obra rezuma tristeza y desilusión por el devenir del pueblo, que se deja llevar por bajas pasiones, y por las maquinaciones y el egoísmo de personajes con poder para manipular a otros. Esas palabras finales del coro dejan abierta la puerta a nuevas incertezas. 
Bañuls Oller, J.V. y Crespo Alcalá, P. (2003): "La arquitectura de la heroína trágica en Sófocles». En De Martino, F. y Morenilla, C. (eds.): L'ordim de la llar. Bari, Levante Editori, págs. 31-102.

Bañuls Oller, J.V., Crespo Alcalá, P. y Morenilla Talens, C. (2007): Electra de Sófocles y las primeras recreaciones hispanas. Bari, Levante Editori.

Bazán Rodríguez, O. (2015): "Las dos Celamas de Luis Mateo Díez». Castilla: Estudios de Literatura, 6, págs. 72-93.

Bernabé Pajares, A. y Casadesús i Bordoy, F. (2008): Orfeo y la tradición órfica: un encuentro. Madrid, Akal.

Bonnéric, H. (1986): La famille des Atrides dans la littérature française. Paris, Les Belles Lettres.

Bravo Castillo, J. (2008): "El mito de Electra en Giraudoux y Sartre». En Herrero Cecilia, J. y Morales Peco, M. (eds.): Reescrituras de los mitos en la literatura: estudios de mitocrítica y de literatura comparada. Cuenca, Universidad de Castilla-La Mancha, págs. 67-81.

Brioso Sánchez, M. (1995): “El concepto del Más Allá entre los griegos». En Piñero Ramirez, P.M. (ed.): Descensus ad inferos. La aventura de ultratumba de los héroes (de Homero a Goethe). Sevilla, Universidad de Sevilla, págs. 1-53.

Carpenter, R. (1946): Folk Tale, Fiction and Saga in the Homeric Epics. Berkely-Los Angeles, University of California.

Carvalho, H.M. (2015): "O mito instável de Orestes e Hamlet». En Pena, A.N. et al. (eds.): Revisitar o mito. Myths Revisited. Ribeirão, Edições Húmus, págs. 363-372.

De Santis, G. (2013): "De estos rostros espantosos veo un gran provecho para los ciudadanos». En Da Silva Duarte, A. y De Almeida Cardoso, Z. (eds.): A representação dos deuses e do sagrado no teatro greco-latino. São Paulo, Humanitas, págs. 11-48.

Frenzel, E. (1992): Stoffe der Weltliteratur. Stuttgart, Alfred Kröner Verlag.

- (19924): Motive der Weltliteratur. Stuttgart, Alfred Kröner Verlag.

Garnier, B. (1999): Pour une poétique de la traduction. L'Hécube d'Euripide en France, de la traduction humaniste à la tragedie classique. Paris-Montréal, L'Harmattan.

Giraudoux, J. (1985): Électre. Paris, Bernard Grasset Éditeur.

Giraudoux, J.-P. (1965): Électre. Paris, Bernard Grasset Éditeur.

Hamburger, K. (1962): Von Sophokles zu Sartre. Griechische Dramenfiguren antik und modern. Stuttgart, W. Kohlhammer Verlag.

Jouanna, D. (2015): Les Grecs aux Enfers. D’Homère à Épicure. Paris, Les Belles Lettres.

Jufresa Muñoz, M. (2006): "Electra, de Jean Giraudoux: un teatro de entreguerras». En Bañuls Oller, J.V., De Martino, F. y Morenilla, C. (eds.): El teatro greco-latino y su recepción en la tradición occidental. Bari, Levante Editori, págs. 269-284.

Luengo López, J. (2013): "De la cruel voluntad del destino y la libertad humana. Algunas visiones de la tragedia clásica en el teatro francés de la primer mitad del siglo xx". Anales de Filología Francesa, 21, págs. 201-223.

Morant Giner, M. (2016): "Reminiscencias de la Orestea en la obra de Héléne Cixous». Tycho, 4, págs. 123-146. 
Morenilla Talens C. (2013): "Tributo a Aristóteles: Edipo Tiranno de Martello". Ágora. Estudos Clássicos em Debate, 15, págs. 113-145.

- (2014): «Ecos ovidianos en una adaptación de Euripides: Hécuba triste de Pérez de Oliva». Synthesis, 21 (en linea: <http: www.synthesis.fahce.unlp.edu.ar> [consulta: 20 de abril de 2017]).

- (2016): «Amory guerra en la tragedia de Sófocles». eClassica, 2: Violéncia no mundo antigo e medieval, págs. 16-34.

Morenilla Talens C. y Bañuls Oller, J.V. (1991): "La propuesta de Eurigania (P. Lille de Estesícoro)". Habis, 22, págs. 63-80.

- (2014): "La vergine innamorata: la Ifigenia, de Euripides a Martello». En Martínez Fernández, A. et al. (eds.): Agalma: ofrenda desde la filología clásica a Manuel García Teijeiro. Valladolid, Universidad de Valladolid, págs. 1219-1232.

Peek, W. (1955): Griechische Vers-Inschriften. Band i: Grab-Epigramme. Berlin, Akademie Verlag.

Suárez de la Torre, E. (1993): "De la lírica al teatro (Observaciones sobre la poesía de Estesícoro)". En: Teatro clásico y teatro europeo. Burgos, Ayuntamiento de Burgos, págs. 3-62. 